\title{
AN INVESTIGATION OF THE ROLE OF THE TEACHER IN GAMIFIED LEARNING IN PRIMARY SCHOOLS
}

\author{
A. Saggah, R. Campion, C. Stanier \\ Staffordshire University (UNITED KINGDOM)
}

\begin{abstract}
Gamification is becoming part of daily life with growing use in the learning context. The research literature shows that gamified learning can have a positive impact on student motivation, and hence there is a need to reflect upon the pedagogic requirements of gamified learning. Furthermore, existing literature acknowledges the value of teachers' input in game design processes; however, evidence also seems to suggest that the teacher's role in gamification design remains undefined and underexplored. For this reason, an investigation was designed to examine primary school teachers' engagement in gamified learning design and categorize the gamification aspects in a learning context from the teacher's perspective. A survey involving sixty-four Saudi Arabian primary school teachers identified gamification aspects which were perceived as teacher-driven tasks in the gamified learning design process. Building on the results of the survey, six in-depth interviews explored how teachers interacted with the gamified learning design process.

The results of the investigation showed that teachers, in general, have a high level grasp of gamification concepts in theory. Teachers positively identified gamification aspects such as the story of the game, rules, timing, and related elements as teacher-driven tasks. However, teachers demonstrated a lack of confidence in applying gamification aspects when asked to complete high level gamification design tasks. For instance, some teachers found the use of gamification input methods and elements such as adding a timing rule for bonus levels as challenging, although they had previously identified these as teacher-driven tasks. In addition, there was a misapplication of concepts, illustrated using in-class rules as gamification rules, i.e., game-specific rules.
\end{abstract}

The research indicated a requirement for a pedagogic gamification framework to support a collaborative strategy between teachers and game developers. A collaborative approach will facilitate teacher involvement in the gamified learning design process, will support better design of the gamification process flow and will enable a better fit to pedagogic requirements. This paper proposes as future work, the development of a pedagogic gamification framework to bridge the gulf between teachers' theoretical knowledge of gamification in education and the practical application of gamification in a school context.

Keywords: Gamification, Gamified learning, Teacher-driven design, Pedagogical gamification, Gamebased learning.

\section{INTRODUCTION}

Gamification generally refers to applying game mechanics and elements into a non-gaming context [1] and [2]. Along similar lines, the concept of "Educational Gamification" is defined as the design strategy of using game design elements in educational contexts to support teaching and learning goals [3] and [4].

With the recent growth in the use of gamification to advance learning experience [5], studies have illustrated the positive influence that game-based learning has on children, including enhancing the engagement element of the course and students' skills. Many published works discuss the design of electronic educational games [6],[2] and [7]. However, there is a lack of clarity about the learning as a process with multiple objectives that includes different parties. Designing an educational game goes beyond game developers and extends to include teachers, students and parents. This paper discusses the attitude of teachers to providing input as domain experts for pedagogical requirements.

This paper discusses the results of an investigation into the readiness of Saudi Arabian primary school teachers to embrace gamification as a concept. The results of the investigation indicated the need for a pedagogic gamification framework to support a collaborative strategy between teachers and game 
developers. This paper proposes as future work, the development of a pedagogic gamification framework to bridge the gulf between teachers' theoretical knowledge of gamification in education and the practical utilization of teachers' expertise in gamification in education.

The paper is structured as follows; section 1 discusses related work about the benefits of gamification in the learning context, pedagogical requirements, the role of teachers as domain experts and existing design tools. Section 2 explains the methodology used in data collection. Section 3 describes the investigation and the findings from the investigation. Finally, Section 4 discusses the analysis, concludes the findings and suggests future work.

\subsection{Benefits of e-games in learning}

Researchers noticed that using an online game course increases students' motivation towards learning [8]. Another study emphasized that students have been more encouraged to learn using mobile game-based learning system [9]. Furthermore, a study described the introduction of a digital learning platform, for pupils in early stages, and provided an interesting form of media that helped students to achieve better results [10]. Another study shows that using a graphical interface, in a library catalog, helped to increase the task completion rate by between $66 \%$ and $100 \%$ based on the children's familiarity with computer usage [11]. Also, [12] suggests that using games positively improved students' motivation, attention, engagement and learning performance

Evidence in current literature suggests that gamification can improve learning performance. For instance, [13] studied the educational value of computer games noted positive psychological resilience among students. Similarly, [14] and [15] emphasized the positive impact of computer games environments to help build anticipation, crisis management and strategizing. Based on the foregoing, this research will investigate teacher engagement in gamification design.

\subsection{Pedagogic requirements and teachers as domain experts}

Current literature identifies in theory teachers' involvement in gamification but fails to clearly define or explain their roles. As [16] suggests, the gamification concept has two levels; the structural level, where educational content remains unchanged when gamification features added such as reward schemes are added. In addition, they identify the content level, where gamification will require a complete transformation of the content using more than one gamification aspect. In other related works, the authors [17], [18], [19], [20] and[21] simply acknowledge the value of teachers' input in the designing process and the pedagogical consideration. Similarly, the authors in [1] and [3] conducted primary research with teachers to set the goals of an e-learning platform. However, the authors make no mention of the implementation of the platform. Moreover, available literature is also limited to discussions on teachers' motivation and their technological savviness; use, design activities and teachers' personal development in relation to use of information and communication technologies (ICT) [22]. The literature shows that while the importance of the teacher's role in relation to gamification is acknowledged, it has not been sufficiently investigated.

\subsection{Existing design tools}

The authors in [6], [2] and [23], show in their research that gamification design tools are scenariobased.

For instance,[7] posits that design tools which integrate the game with outside activities have a significant impact upon the capacity of education. These authors use tables to transfer content associated with the following four-game elements at the pedagogical level; game goal, curriculum goal, previous skills and knowledge enhancement. In addition, another table focuses on the game elements at the information technology (IT) design level such as objects, attribute, feedback, help, narration, score and rules.

Along similar lines, others research by the authors in [24], [1] and [25] provide an overview of the design process, but with no decision supporting guidance. It has been suggested by [26] that Unified Modeling Language (UML) can be used as a modeling tool in the gamification design process. However, the use of UML for this purpose is deemed challenging for teachers, the underlying argument being that UML is a specialist software design tool. Likewise, [20] used the (ADDIE) model, which is a software development tool stands for Analysis - Design - Development - Implementation Evaluation, to build a game considering the pedagogical requirements and motivation, nonetheless with no gamification mechanics. 


\section{METHODOLOGY}

This research applied an explanatory sequential mixed method design which starts the research process by building a solid ground with quantitative strategy and follow up with a qualitative strategy to provide more clarification and provide an in-depth interpretation of the research phenomena [28]

A questionnaire was created to categorize thirteen gamification aspects from a teacher's perspective. These were based on educational, instructional and training game design studied by [29],[30],[31] and [32]. The list did not use a hierarchical approach and the presentation of elements was purposefully random to avoid influencing participants' choices. The aspects considered were:

1. Game idea: the theme and storyline

2. Goals: set number of tasks for pupils to achieve

3. Rules: set main rules for the game

4. Time: allocating each task a session duration

5. Level: structured levels to provide the player with additional interest to succeed each level and move forward

6. Number of players

7. The multimedia elements choices, such as photo, video, audio, text, and animation, etc.

8. Controls: user input methods, such as choosing touch screen or voice command, etc. for output and pupil feedback

9. Add excitement in certain points of the game. Such as adding a timing rule for bonus levels

10. The social engagement: To plan conflict, competition or cooperation with other players as one team or as competitors

11. Reward structure: useful to motivate the players. Such as points system, badges, or top player list

12. Replay option: Allowing the player to repeat the game starting from the last successful level

13. Learning progression: representing the actual student acquisition throughout the game

The survey was carried out with sixty-four Saudi Arabian primary school teachers and was designed to identify gamification aspects, perceived as teacher-driven tasks in the gamified learning design process. Building on the results of the survey, six in-depth interviews explored how teachers interacted with the gamified learning design process. The interviews were used to validate the findings of the survey. The interviews used the thirteen gamification aspects, previously in the survey and teachers were asked to identify tasks are perceived as teacher-driven tasks in the gamified learning design process. The interview participants were then asked to perform a design task by sketching a simple game interface using the same list of gamification aspects. The sketches were used to compare the initial choices to the actual utilization.

\section{THE INVESTIGATION AND THE FINDINGS FROM THE INVESTIGATION}

\subsection{Survey}

There were 64 completed responses consisted of both genders equally all are primary school teachers, $81 \%$ of them are public school teachers. Teaching experience ranging from three months to thirty years and covered all the curriculum. However, $45 \%$ of the respondents used electronic games. Only $14 \%$ of the respondents tried developing electronic games themselves. Moreover, among them, $55 \%$ acknowledged they had found guidelines addressed to teachers. The information provided was difficult to find, except one response. The participant stated three general guidelines. Based on the survey aspects are categorized as teacher-driven, game developers and shared tasks, as illustrated in Table 1. 
Table 1. Summary of survey findings.

\begin{tabular}{|c|c|}
\hline & Gamification aspects \\
\hline \multirow{8}{*}{$\begin{array}{l}\text { Teacher- } \\
\text { driven }\end{array}$} & Game idea: the theme and storyline \\
\hline & Goals: set number of tasks for pupils to achieve \\
\hline & Rules: set main rules for the game \\
\hline & Time: allocating each task a session duration \\
\hline & Number of players \\
\hline & The multimedia elements choices, such as photo, video, audio, text, and animation, etc. \\
\hline & $\begin{array}{l}\text { Reward structure: useful to motivate the players. Such as points system, badges, or top } \\
\text { player list }\end{array}$ \\
\hline & Learning progression: representing the actual student acquisition throughout the game \\
\hline \multirow[t]{3}{*}{$\begin{array}{l}\text { Game } \\
\text { developer }\end{array}$} & $\begin{array}{l}\text { Controls: user input methods, such as choosing touch screen or voice command, etc. for } \\
\text { output and pupil feedback }\end{array}$ \\
\hline & $\begin{array}{l}\text { Add excitement in certain points of the game. Such as adding a timing rule for bonus } \\
\text { levels }\end{array}$ \\
\hline & $\begin{array}{l}\text { Replay option: Allowing the player to repeat the game starting from the last successful } \\
\text { level }\end{array}$ \\
\hline \multirow[t]{2}{*}{ Shared } & $\begin{array}{l}\text { Level: structured levels to provide the player with additional interest to succeed each level } \\
\text { and move forward }\end{array}$ \\
\hline & $\begin{array}{l}\text { The social engagement: To plan conflict, competition or cooperation with other players as } \\
\text { one team or as competitors }\end{array}$ \\
\hline
\end{tabular}

\subsection{Interview}

This section validates the survey and presents a discussion of the interview findings. The gamification aspects considered in the survey (Table 1 in Section 3.1 above) were also considered in the current section. During the interview, teachers were asked to identify tasks they perceived as "teacher-driven" in the gamified learning design process. Numerous teacher-driven tasks are classified during the survey (See Table 1 above); nonetheless, four (4) aspects remain consistent across the interviews (See Table 2). Aspects in this sense are goals, number of players, timing and multimedia choice. Furthermore, keeping the excitement curve remained a game developer's task. In the following, the participants were asked to sketch a basic game interface using the same list of gamification aspects. The sketch would provide material to compare the initial categorization with practical utilization. A thematic analysis was conducted because it supports patterns identification. The analysis identified the following four main themes: Teachers' understanding of gamification as a concept, Gamification aspects classified as teacher-driven, Teachers utilization of gamification aspects and the misapplication of concepts. The interview findings are summarised in Table 2 below.

Table 2. Summary of interview findings

\begin{tabular}{|l|l|}
\hline & Gamification aspects \\
\hline Teacher- & Goals: set number of tasks for pupils to achieve \\
\hline
\end{tabular}




\begin{tabular}{|c|c|}
\hline \multirow[t]{7}{*}{ driven } & $\begin{array}{l}\text { Level: structured levels to provide the player with additional interest to succeed each } \\
\text { level and move forward }\end{array}$ \\
\hline & $\begin{array}{l}\text { The social engagement: To plan conflict, competition or cooperation with other } \\
\text { players as one team or as competitors }\end{array}$ \\
\hline & Time: allocating each task a session duration \\
\hline & Number of players \\
\hline & $\begin{array}{l}\text { The multimedia elements choices, such as photo, video, audio, text, and animation, } \\
\text { etc. }\end{array}$ \\
\hline & $\begin{array}{l}\text { Reward structure: useful to motivate the players. Such as points system, badges, or } \\
\text { top player list }\end{array}$ \\
\hline & Game idea: the theme and storyline \\
\hline \multirow{2}{*}{$\begin{array}{l}\text { Game } \\
\text { developer }\end{array}$} & Rules: set main rules for the game \\
\hline & $\begin{array}{l}\text { Add excitement in certain points of the game. Such as adding a timing rule for bonus } \\
\text { levels }\end{array}$ \\
\hline \multirow[t]{3}{*}{ Shared } & $\begin{array}{l}\text { Replay option: Allowing the player to repeat the game starting from the last } \\
\text { successful level }\end{array}$ \\
\hline & $\begin{array}{l}\text { Learning progression: representing the actual student acquisition throughout the } \\
\text { game }\end{array}$ \\
\hline & $\begin{array}{l}\text { Controls: user input methods, such as choosing touch screen or voice command, etc. } \\
\text { for output and pupil feedback }\end{array}$ \\
\hline
\end{tabular}

\subsubsection{Teachers understanding of gamification as a concept}

The investigation showed that participants in general, had a high level grasp of gamification concepts at a theoretical level. All the teachers in the interview acknowledged gamification as a powerful tool to keep the students engaged in class. All the teachers in the interviews were already using some form of non-electronic gamification scheme in class such as reward structure, leaderboard and social planning cooperation between team members.

Participants' utilization of some gamification aspects showed differing levels of understanding. This was reflected clearly in the game idea and general story; all participants agreed that having a game story will improve students' engagement. Of the six (6) teachers who took part in the interview, only one was able to ultimately connect up the game as a story through the screens and follow up the presentation of the rewards system as a group as part of the gamified learning sample. Interestingly, she initially identified inventing a story as a shared task with the developer, however, during the task design, the role of the developer was not recognized. Two of the participants started the design with a story line, however, was not utilized further to connect other elements of the game. Two of the participants perceived the game story as a teacher-driven task. However, during the task design, both participants did not refer to any story, but instead, the tasks were independent questions on a screen. The balance of choice was offered in one of the participants where the story was perceived as a shared task. Also, during task design, acknowledged the importance of having a story, and a character might positively affect the student's attitude and referred to the developer expertise in this aspect.

\subsubsection{Gamification aspects classified as teacher-driven}

Gamification aspects were examined at two different points. Initially, participants categorized aspects theoretically, as teacher-driven, game developer or shared tasks. Following that, a practical task was used in which participants were asked to complete high-level gamification design tasks utilizing 
aspects which demonstrated different categorization. This identified subthemes where some of the aspects initially classified as teacher driven were utilized in task design and some were not utilized.

Teacher-driven tasks utilized during the task design.

This section elaborates on aspects that were initially considered as teacher-driven and later utilized practically during task design. All participants instinctively identified goal(s) of the game and game levels from the easiest to the most challenging. Participants instincts were informed from the resemblance to traditional lesson preparation. However, participants afterward started to consult the gamification aspects list provided, to proceed to the next design decision. The aspects fall into this theme are timing, multimedia choices and planning the social engagement if applicable. The multimedia choices were made by teachers during the task design although three participants recognized the importance of the developer's input, stating that their choices are provisional subject to the developer's insights in such a stage.

Teacher-driven tasks not utilized during the task design.

In this sub-theme, teachers wanted to take the decision initially, however, during task design participants avoided these tasks. This relates to the use of a replay option and progression presentation.

All participants agreed that the Replay option, Allowing the player to repeat the game starting from the last successful level without the need to start all over the beginning, is a teacher-driven task. One participant emphasized that keeping the student from progressing through the game is off-putting and should not be considered as progression condition to move to the next screen. In the end, four out of six teachers did not refer to this functionality in the task design. Teachers' responses varied regarding progression presentation; three participants identified it as teacher-driven and one as a shared task, theoretically during initial categorization. However, during task design, only one participant included this aspect.

\subsubsection{Teachers utilization of gamification aspects}

During the interviews, thirteen gamification aspects were explained, and illustrated with an example, if necessary. Teachers were asked to categorize gamification aspects into teacher-driven, game developer or shared task from their perspective in the designing process. The participants gave categorized aspects and their individual choices varied from five to ten out of thirteen aspects overall to be teacher-driven tasks. Afterward, initial categorizations were compared to teachers' utilization of during the task design followed.

Participants agreed that the role of a game developer is critical during the design phase and also in the implementation of the game. However, during the design stage teachers' pedagogic and domain knowledge is considered more critical. Teachers referred to aspects such as keeping the engagement curve and provoking excitement in specific points of the game as tasks to be strategized by game developers. Specifically, during the task design, two teachers acknowledged lack of experience in keeping the interest curve and deferred to the experience of a game developer in this area. Meanwhile, four teachers decided to leave this task to the game developer although two of them had initially considered it as a teacher-driven task.

\subsubsection{The misapplication of concepts}

This describes some aspects where the transformation into gamified learning required a different perception of concepts and participants' utilization was misapplied. This theme comprises two aspects providing game rules and define rewarding mechanism. This is illustrated by the fact that the rules provided by the teachers, if any, were either disciplinary or navigation controllers. However, both types are not game rules to engage the students.

Participants acknowledged the importance of rewards either individually or shared socially hence five out of six referred to it as a teacher-driven task. During the task design, three out of six set a rewarding mechanism or referenced where it would be beneficial. Only one of the participants misapplied the concept by using a non-electronic form, i.e., treat from the box type. 


\section{CONCLUSIONS}

As gamification is becoming commonplace in learning, this paper sought to investigate primary school teachers' involvement in the gamified learning design process to identify their perspectives. This is significant as a precursor to future directions towards gamified learning environments for Primary School Teachers. Available literature shows that gamified learning can have a positive impact on student motivation. Two investigations; a survey of 64 Primary school teachers, and subsequent interviews involving 6 Primary school teachers were conducted in Saudi Arabia, and yielded interesting results. Foremost, investigation findings identify the gamification context relative ease, suggesting most as technologically savvy. In addition, there is a gap between the theory and practice of gamification as reflected at the evolvement of classification decision.

This paper found that teachers' decisions about gamification aspects categorization evolved as the teachers came to understand the complexity of the game design. The task design exercise resulted in two types of utilization, instinctive and conscious. Firstly, instinctive where participants are confident utilizing without guidance such as goals and levels due to highly relation to pedagogic aspects. However, moving towards the game design, they were less confident therefore used the supporting list which represents conscious utilization. This applies to gamification aspects such as timing, multimedia choices and planning the social engagement. Although replay option and progression presentation were identified initially as teacher-driven tasks, participants chose against utilizing them. The underlying argument is that there were more critical tasks to be addressed by a teacher. Furthermore, the task design exercise indicated an overall tendency to lose direction through the design process which was clear while consulting the provided aspects list. Although teachers showed confidence in being the key person in designing an educational game, there was a need for a workflow of the process to enable teachers to participate fully in the design process.

Findings yielded in this paper show that teachers who already use electronic games in classroom environments appreciate the game developers' role. Aspects such as keeping the engagement curve and implementing rules are considered developers' tasks. Interestingly, how teachers categorize game rules as a gamification aspect aligned with [29] that defines foundational rules as controllers of the workflow and assigned to the game developer. Moreover, using the correct answer as the only navigation controller, as suggested by a participant, causes frustration for students.

The research indicated a requirement for a pedagogic gamification framework to support a collaborative strategy between teachers and game developers. A collaborative approach will facilitate teacher involvement in the gamified learning design process, will support better design of the gamification process flow and will enable a better fit to pedagogic requirements. This paper proposes as future work, the development of a pedagogic gamification framework to bridge the gulf between teachers' theoretical knowledge of gamification in education and the practical application of gamification in a school context.

According to [16] the gamification concept has two levels structural and content. In a structural level approach, the educational content remains the same while some gamification features are added such as reward schemes. The content level of gamification will require transforming the content all together using more than one gamification aspect. The teachers who took part in this study have a good grasp of game concepts, but this did not necessarily translate into practice, as illustrated by aspects such as the use of the game story. Participants' utilization of gamification aspects showed an understanding of structural gamification level and lacked the depth of impact on engagement and during the task design.

In conclusion, primary research indicates the need for a pedagogic gamification framework to support a collaborative strategy between teachers and game developers. A collaborative approach to facilitate teacher engagement in the design process, support better design of the gamification process flow and will enable a better fit to pedagogic requirements. As noted by the authors in [3], teachers as the domain content and context experts, have to become co-developers in the gamification process. This 
paper proposes as future work, the development of a pedagogic gamification framework to bridge the gulf between teachers' theoretical knowledge of gamification in education and the practical utilization.

\section{REFERENCES}

[1] S. Mystakidis, N. Lambropoulos, H. M. Fardoun, and D. M. Alghazzawi, "Playful Blended Digital Storytelling in 3D Immersive eLearning Environments," in Proceedings of the 2014 Workshop on Interaction Design in Educational Environments - IDEE '14, 2014, pp. 97-101.

[2] K. Browne, C. Anand, and E. Gosse, "Gamification and serious game approaches for adult literacy tablet software," Entertain. Comput., vol. 5, no. 3, pp. 135-146, Aug. 2014.

[3] A. Botha and M. Herselman, "ICTs in Rural Education," in Proceedings of the 2015 Annual Symposium on Computing for Development - DEV '15, 2015, pp. 105-113.

[4] A. Botra, M. Rerselman, and M. Ford, "Gamification beyond badges," in 2014 IST-Africa Conference Proceedings, 2014, pp. 1-10.

[5] M. Guerreiro and C. Nordengren, "'No Fun Games': Engagement Effects of Two Gameful Assessment Prototypes," J. Res. Technol. Educ., pp. 1-15, Feb. 2018.

[6] R. N. Landers and M. B. Armstrong, "Enhancing instructional outcomes with gamification: An empirical test of the Technology-Enhanced Training Effectiveness Model," Comput. Human Behav., vol. 71, pp. 499-507, Jun. 2017.

[7] A. G. Safitri, A. S. Prihatmanto, and P. H. Rusmin, "Design and implementation of educational game based on thematic curriculum using three layered thinking model (Case study: Applying number and social arithmetic in the real life)," in 2015 4th International Conference on Interactive Digital Media (ICIDM), 2015, pp. 1-7.

[8] C.-H. Lai, Y.-C. Lin, B.-S. Jong, and Y.-T. Hsia, "Adding Social Elements to Game-Based Learning," Int. J. Emerg. Technol. Learn., vol. 9, no. 3, p. 12, 2014.

[9] W.-C. Lin, J.-Y. Ho, C.-H. Lai, and B.-S. Jong, "Mobile game-based learning to inspire students learning motivation," 2014 Int. Conf. Inf. Sci. Electron. Electr. Eng., pp. 810-813, 2014.

[10] I. a. Zualkernan, S. Lutfeali, and A. Karim, "Using tablets and satellite-based internet to deliver numeracy education to marginalized children in a developing country," IEEE Glob. Humanit. Technol. Conf. (GHTC 2014), pp. 294-301, 2014.

[11] K. Wu, Y. Tang, and C. Tsai, "Graphical interface design for children seeking information in a digital library," Vis. Eng., vol. 2, no. 1, p. 5, 2014.

[12] C. Morillas Barrio, M. Munoz-Organero, and J. Sanchez Soriano, "Can Gamification Improve the Benefits of Student Response Systems in Learning? An Experimental Study," IEEE Trans. Emerg. Top. Comput., vol. 4, no. 3, pp. 429-438, Jul. 2016.

[13] A. Dumitrache and B. Almăşan, "Educative Valences of Using Educational Games in Virtual Classrooms," Procedia - Soc. Behav. Sci., vol. 142, pp. 769-773, 2014.

[14] J. ter Vrugte, T. de Jong, S. Vandercruysse, P. Wouters, H. van Oostendorp, and J. Elen, "How competition and heterogeneous collaboration interact in prevocational game-based mathematics education," Comput. Educ., vol. 89, pp. 42-52, 2015.

[15] P. J. C. Adachi and T. Willoughby, "The Link Between Playing Video Games and Positive Youth Outcomes," Child Dev. Perspect., vol. 11, no. 3, pp. 202-206, Sep. 2017.

[16] A. Darejeh and S. S. Salim, "Gamification Solutions to Enhance Software User Engagement A Systematic Review," Int. J. Hum. Comput. Interact., vol. 7318, no. May, p. 10447318.2016.1183330, 2016.

[17] C. S. González, N. Gómez, V. Navarro, M. Cairós, C. Quirce, P. Toledo, and N. MarreroGordillo, "Learning healthy lifestyles through active videogames, motor games and the gamification of educational activities," Comput. Human Behav., vol. 55, pp. 529-551, Feb. 2016.

[18] D. Kayımbaşıoğlu, B. Oktekin, and H. Hacı, "Integration of Gamification Technology in Education," Procedia Comput. Sci., vol. 102, pp. 668-676, Jan. 2016. 
[19] D. Kermek, D. Strmecki, M. Novak, and M. Kaniski, "Preparation of a hybrid e-learning course for gamification," in 2016 39th International Convention on Information and Communication Technology, Electronics and Microelectronics (MIPRO), 2016, pp. 829-834.

[20] T. Bouzid, H. Darhmaoui, and F. Kaddari, "Promoting elementary mathematics learning through digital games," in Proceedings of the 2nd international Conference on Big Data, Cloud and Applications - BDCA'17, 2017, pp. 1-4.

[21] A. Gordillo, D. Gallego, E. Barra, and J. Quemada, "The city as a learning gamified platform," in 2013 IEEE Frontiers in Education Conference (FIE), 2013, pp. 372-378.

[22] J. Hamari and T. Nousiainen, "Why Do Teachers Use Game-Based Learning Technologies? The Role of Individual and Institutional ICT Readiness," in 2015 48th Hawaii International Conference on System Sciences, 2015, pp. 682-691.

[23] J. Simões, R. D. Redondo, and A. F. Vilas, "A social gamification framework for a K-6 learning platform," Comput. Human Behav., vol. 29, no. 2, pp. 345-353, Mar. 2013.

[24] P. Lameras and N. Moumoutzis, "Towards the gamification of inquiry-based flipped teaching of mathematics a conceptual analysis and framework," in 2015 International Conference on Interactive Mobile Communication Technologies and Learning (IMCL), 2015, pp. 343-347.

[25] A. Gaber, O. A. Naseef, and N. Abdelbaki, "Creating an innovative generic virtual learning lab," in 2013 World Congress on Computer and Information Technology (WCCIT), 2013, pp. 1-6.

[26] K. M. L. Cooper and W. Scacchi, Computer games and software engineering. Boca Raton: CRC Press, 2015.

[27] D. Ašeriškis and R. Damaševičius, "Gamification Patterns for Gamification Applications," Procedia Comput. Sci., vol. 39, pp. 83-90, Jan. 2014.

[28] J. W. Creswell, Research design: qualitative, quantitative, and mixed methods approaches. SAGE Publications, 2014.

[29] K. M. Kapp, The Gamification of Learning and Instruction. San Francisco: Pfeiffer, 2012.

[30] R. Senderek, B. Brenken, and V. Stich, "The implementation of game based learning as part of the corporate competence development," in 2015 International Conference on Interactive Collaborative and Blended Learning (ICBL), 2015, pp. 44-51.

[31] O. Noran and Ovidiu, "On gamification in action learning," in Proceedings of the Australasian Computer Science Week Multiconference on - ACSW '16, 2016, pp. 1-9.

[32] R. Garett and S. D. Young, "Health Care Gamification: A Study of Game Mechanics and Elements," Technol. Knowl. Learn., pp. 1-13, Jan. 2018. 